\title{
Investigation of Lactobacillus Casei and Lactobacillus Acidophilus Amount at Gut Microbiota from Adult Type 1 Diabetes Mellitus Patients
}

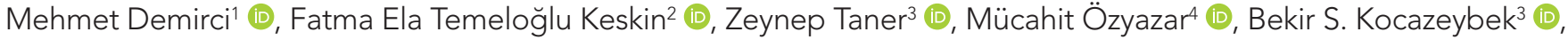 \\ Hrisi Bahar Tokman³ \\ 'Department of Medical Microbiology, Beykent University School of Medicine, İstanbul, Turkey \\ 2Department of Endocrinology and Metabolic Diseases, University of Health Sciences Gaziosmanpaşa Taksim Training and Research Hospital, istanbul, Turkey \\ ${ }^{3}$ Department of Medical Microbiology, İstanbul University-Cerrahpaşa, Cerrahpaşa School of Medicine, İstanbul, Turkey \\ ${ }^{4}$ Department of Endocrinology and Metabolic Diseases, Yeni Yüzyıl University Gaziosmanpaşa Hospital, İstanbul, Turkey
}

Cite this article as: Demirci M, Temeloğlu Keskin FE, Taner Z, Özyazar M, Kocazeybek BS, Tokman HB. Investigation of Lactobacillus Casei and Lactobacillus Acidophilus Amount at Gut Microbiota from Adult Type 1 Diabetes Mellitus Patients. JAREM 2019; 9(3): $125-9$.

\begin{abstract}
Objective: The aim of this study were to determine the amount of Lactobacillus acidophilus and Lactobacillus casei, which are considered to have protective roles among the host-gut microbiota due to their probiotic properties, by using real-time polymerase chain reaction (PCR) and to compare between adult patients with type 1 diabetes mellitus (T1DM) and healthy individuals.

Methods: Between January 2014 and October 2014, a total of 106 stool samples comprising those of 53 adult patients who were diagnosed with T1DM and those of 53 healthy individuals who presented to an endocrinology clinic were included in the study. DNA was isolated from the stool samples and analyzed with specific primers for L. acidophilus and L. casei by real-time PCR. Statistical analyses, such as Mann-Whitney U test, were used to determine the difference among patients with T1DM and healthy individuals.

Results: The mean age of patients with T1DM and healthy individuals participating in the study was $32.87 \pm 12.68$. A statistically significant difference was observed in the body mass index (BMI) and levels of HbA1c and fasting blood sugar of patients with T1DM when compared to those of the healthy individuals $(p<0.001)$. Conversely, no statistically significant difference was observed in the amount of $L$. acidophilus and $L$. casei detected in the gut of patients with T1DM when compared to that detected in the gut of healthy individuals $(p>0.05)$.

Conclusion: This study was the first to determine and compare the amounts of $L$. acidophilus and $L$. casei in the gut of patients with T1DM and healthy individuals. The amount of these bacteria with known probiotic activities is not different among patients with T1DM and healthy individuals, and there is no change in the amount of these bacteria in both the reciprocal triggering cycle of T1DM and gut microbiota. This situation needs to be clarified with comprehensive studies.
\end{abstract}

Keywords: L. acidophilus, L. casei, gut microbiota, real-time PCR, type 1 diabetes

\section{INTRODUCTION}

Type 1 diabetes mellitus (T1DM) is an autoimmune disease with a multifactorial character and is a major global illness (1). A complex interaction of genetic and environmental factors can lead to T1DM (2). The human intestinal lumen contains microbiota of the order $10^{14}$ microorganisms $/ \mathrm{mL}$; this microbiota contributes to the development of diabetes as an environmental factor through intestinal immune activation $(3,4)$. Since the intestinal microbiota plays a major role in the normal development of both innate and acquired immune systems $(5,6)$, it affects various metabolic functions in an individual (7) and is increasingly considered that human and animal models play an important role in the develop- ment of metabolic diseases, the focus has been in the intestinal microbiota in recent years (5). Probiotics are defined as living organisms with host health-enhancing effects. Probiotics have been shown to activate dendritic cells, macrophages, and monocytes in vitro and thus affect the immune system (8). Many organisms among the Lactobacillus species members are used as commercial probiotics. L. acidophilus and L. casei are some of the species with proven probiotic potential (9), which are considered to have protective roles. Hence, we aimed to determine the number of bacteria in adult T1DM patients and healthy control groups in the present study using the real-time polymerase chain reaction (PCR) method and determine the difference between the groups. 


\section{METHODS}

\section{Creation of Study Groups}

This study was conducted between January 2014 and October 2014 in the Department of Medical Microbiology with stool samples of 53 adult patients who were admitted to the Department of Endocrinology and were diagnosed with T1DM and 53 stool samples from the healthy participants comprising the control group. Approval was obtained from the clinical trials ethics committee (Date: October, 31, 2013, decision No: 83045809/30339). Written informed consent was obtained from each patient and healthy controls included in the study.

The pairing method was used during data analysis to prevent the occurrence of bias. Hence, the participants of the control group were matched in terms of age and sex to the patient group after collecting the patient group cases. The age range of the disease control center (CDC), which was determined according to the rate of diabetes diagnosis (10), was used to determine the age ranges for grouping the patients and controls.

Individuals who had no disease other than T1DM, were not obese, had not used antibiotics in the last 2 weeks, had not used probiotics in the last month, were adolescents (>18 years old), and whose parents were not diagnosed with T1DM were included in the present study.

\section{Collection and Preservation of Samples}

Stool samples were collected in plastic stool containers, brought to the laboratory immediately, and stored at $-20^{\circ} \mathrm{C}$ until bacterial DNA isolation procedures were performed.

\section{DNA Isolation from Stool Samples}

Isolation of bacterial DNA from stool samples was performed using Magna Pure 96 DNA and Viral NA Small Volume kit (Roche Diagnostics GmBH, Mannheim, Germany) and Stool samples transport and recovery solution (STARbuffer) (Roche Diagnostics $\mathrm{GmBH}$ ) with Magna Pure 96 (Roche Diagnostics $\mathrm{GmBH}$ ) by following the manufacturer's instructions. The resulting DNA was checked using a nanodrop spectrophotometer (Nanodrop Technologies, Wilmington, DE, USA), and its concentrations at 260 $\mathrm{nm}$ and purity at 260/280 $\mathrm{nm}$ were measured.

\section{Production of Bacterial Control Strains and Establishment of Plasmid Standards}

In real-time PCR studies, the standard origins of ATCC 4356 for L. acidophilus and ATCC 393 for L. casei were used as positive controls and for the creation of real-time PCR standard curves by generating plasmid standards. To produce control strains, $L$. acidophilus ATCC 4356 and L. casei ATCC 393 were cultured in enriched Schaedler agar medium and Rogosa agar (Fluka, Sigma, Switzerland) in the laboratory. The inoculated media were incubated in anaerobic jars with anaerobic environment supplies (Oxoid Anaerogen, BD GasPak EZ Anaerobe Container System) for 72 hours at $37^{\circ} \mathrm{C}$. To establish plasmid standards, pure colonies after 48 hours of incubation were taken in a sterile loop and separately inoculated into a $1 \mathrm{~mL}$ sodium phosphate buffer in microcentrifuge tubes. The density was set for 1 McFarland. The plasmid standards prepared from these strains by Bioeksen Ltd (Istanbul, Turkey) were used to create a standard curve in realtime PCR.

\section{Determination of the Amount of L. acidophilus and L. casei Using Real-Time PCR}

To determine the concentration of $L$. acidophilus and $L$. casei from DNA, PCR was carried out with heat shock protein 60 (Table 1) and using the specific primers and probes of the GroEL region. The amount of reagents loaded in each reaction mixture according to the manufacturer's directives is shown in Table 2. The LightCycler 480 II (Roche Diagnostics $\mathrm{GmBH}$ ) real-time PCR system with the Fast Start Essential Probe Master Mix kit (Roche Diagnostics GmBH) (11, 12) was used. For each reaction, $5 \mu \mathrm{L}$ of bacterial DNA was used.

The PCR profile was achieved by an initial activation phase: at $95^{\circ} \mathrm{C}$ for 10 minutes, followed by 45 cycles of denaturation, elongation, and replication stages performed at $95^{\circ} \mathrm{C}$ for 10 seconds, at $60^{\circ} \mathrm{C}$ for 30 seconds, and at $72^{\circ} \mathrm{C}$ for 1 second, respectively. The experiment was performed in triplicates for each sample. The PCR device automatically evaluated the Cp value of each sample in real-time based on the standard curve obtained by the plasmid standards, and the number of bacteria was measured.

\section{Statistical Analysis}

In our study, the differences in L. acidophilus and L. casei determined from stool samples of T1DM patients and control participants were estimated using the Mann-Whitney $U$ analysis in the IBM ${ }^{\circledR}$ Statistical Package for Social Sciences 20.0 software (IBM Corp., Armonk, NY, USA).

\section{RESULTS}

In this study, 53 patients with T1DM and 53 healthy individuals were included; 28 of the patients were males and 25 were females. The mean age of the patients in our study was $32.87 \pm 12.68$ years. Healthy controls were matched with patients and 28 were males and 25 were females, with an mean age of $32.87 \pm 12.68$ years, similar to the patients.

The mean body mass index (BMI) in the healthy control group was $20.23 \pm 1.70 \mathrm{~kg} / \mathrm{m}^{2}$, while it was $23.25 \pm 1.63 \mathrm{~kg} / \mathrm{m}^{2}$ in the T1DM group. The mean glycated hemoglobin ( $\mathrm{HbA} 1 \mathrm{c}$ ) level was $4.19 \pm 1.11 \%$ in the healthy control group and $8.69 \pm 1.91 \%$ in the T1DM patient group. The fasting plasma glucose (FPG) was $91.0 \pm 5.67 \mathrm{mg} / \mathrm{dL}$ in the healthy control group and $133.4 \pm 62.44$ $\mathrm{mg} / \mathrm{dL}$ in the T1DM patient group. The BMI, HbA1c, and FPG levels in the patients showed a statistically significant difference compared to healthy controls ( $p<0.001$; Table 3 ).

No statistically significant differences were determined between T1DM male and female patients and healthy controls in all age groups in terms of the concentration of $L$. acidophilus and $L$. casei found in 1 gram of stool ( $p>0.05$ ). Figures 1 and 2 show the growth curves obtained from the real-time PCR study for $L$. casei and L. acidophilus.

Furthermore, the average values of the concentrations of $\log _{10}$ L. acidophilus and L. casei obtained from 1 gram of stool based on the real-time PCR analysis indicated that the amount of L. acidophilus and L. casei detected in male patients did not show a statistically significant difference in all age groups compared to healthy controls ( $p>0.05)$. Regardless of the age groups, there was no statistically significant difference in the amount of L. acidophilus and L. casei found in all T1DM male patients compared to the healthy control group ( $p>0.05$; Table 4).

Similarly, when the average values of the amounts of $\log _{10} L$. acidophilus and $L$. casei for females in the T1DM patient and healthy control 
Table 1. Primer sets used to determine the amount of $L$. acidophilus and $L$. casei through real-time PCR

\begin{tabular}{|l|l|c|}
\hline Primer name & Sequence & Reference \\
\hline L. acidophilus F & 5' ATGGAAAAGGTTGGCCA3' & 11 \\
\hline L. acidophilus $R$ & 5' TCAGTTACCATGTATTGTGACA3' & 11 \\
\hline L. acidophilus Prob & FAM'TCGAAGATTCACGTGGTATCAATAC'Tamra & 11 \\
\hline L.casei F & 5'CTATAAGTAAGCTTTGATCCGGAGATTT3' & 12 \\
\hline L.casei $R$ & 5'CTTCCTGCGGGTACTGAGATGT3' & 12 \\
\hline L.casei probe & Fam'ACAAGCTATGAATTCACTTGC'Tamra & 12 \\
\hline F: forward primer; R: reverse primer; PCR: polymerase chain reaction; L.: Lactobacillus & \\
\hline
\end{tabular}

Table 2. L. acidophilus and L. casei master mix preparation protocol

\begin{tabular}{|l|c|}
\hline Material & Amount \\
\hline PCR quality water & $4.7 \mu \mathrm{L}$ \\
\hline L. acidophilus or L. casei primer F & $0.1 \mu \mathrm{L}$ \\
\hline L. acidophilus or L. casei primer $R$ & $0.1 \mu \mathrm{L}$ \\
\hline L.acidophilus probe & $0.1 \mu \mathrm{L}$ \\
\hline Prob master & $10 \mu \mathrm{L}$ \\
\hline Total amount & $15 \mu \mathrm{L}$ \\
\hline F: forward primer; R: reverse primer; PCR: polymerase chain reaction; L.: \\
\hline Lactobacillus
\end{tabular}

Table 3. Comparison of demographic data of patients and healthy controls

\begin{tabular}{|c|c|c|c|}
\hline Characteristics & $\begin{array}{l}\text { T1DM } \\
\text { patients } \\
\mathrm{n}: 53\end{array}$ & $\begin{array}{l}\text { Healthy } \\
\text { control } \\
\text { group n:53 }\end{array}$ & $p^{\star \star}$ \\
\hline Male/female & $28 / 25$ & $28 / 25$ & \\
\hline Age* (years) & $32.87 \pm 12.68$ & $32.87 \pm 12.68$ & 1.000 \\
\hline $\mathrm{BMI}\left(\mathrm{kg} / \mathrm{m}^{2}\right)$ & $23.25 \pm 1.63$ & $20.23 \pm 1.70$ & 0.000 \\
\hline HbA1c (\%) & $8.69 \pm 1.91$ & $4.19 \pm 1.11$ & 0.000 \\
\hline $\mathrm{FPG}(\mathrm{mg} / \mathrm{dL})$ & $133.4 \pm 62.44$ & $91.0 \pm 5.67$ & 0.000 \\
\hline
\end{tabular}

groups in terms of age were examined, no statistically significant difference was noted in 19-28, 31-41, and 43-56 years' age groups compared to healthy control group ( $p>0.05$ ). Regardless of age groups, there was no statistically significant difference in the amount of $L$. acidophilus and $L$. casei found in all T1DM female patients compared to the healthy control group ( $p>0.05, p>0.05$; Table 5).

\section{DISCUSSION}

T1DM, considered the most common endocrine disease in the world, is a multifactorial, autoimmune disease caused by genetic and environmental factors $(1,2)$. In recent years, developments
Table 4. Comparison of $L$. acidophilus and $L$. casei in male patients and male controls in terms of age

\begin{tabular}{|l|c|c|c|c|}
\hline & $\begin{array}{c}\text { Age } \\
\text { groups } \\
\text { (years) }\end{array}$ & $\begin{array}{c}\text { T1DM } \\
\text { patients }\end{array}$ & $\begin{array}{c}\text { Healthy } \\
\text { control } \\
\text { group }\end{array}$ & $\begin{array}{c}\text { p } \\
\text { value* }\end{array}$ \\
\hline \multirow{2}{*}{ L. acidophilus } & $19-29$ & $4.86 \pm 0.22$ & $4.85 \pm 0.21$ & 0.852 \\
\cline { 2 - 5 } & $31-44$ & $4.93 \pm 0.08$ & $4.93 \pm 0.12$ & 0.833 \\
\hline & $49-61$ & $4.96 \pm 0.15$ & $4.97 \pm 0.14$ & 0.834 \\
\hline \multirow{2}{*}{ L. casei } & All ages & $4.90 \pm 0.18$ & $4.89 \pm 0.18$ & 0.854 \\
& $19-29$ & $4.19 \pm 0.19$ & $4.23 \pm 0.17$ & 0.361 \\
\hline & $31-44$ & $4.18 \pm 0.22$ & $4.37 \pm 0.24$ & 0.156 \\
\cline { 2 - 6 } & $49-61$ & $4.35 \pm 0.19$ & $4.33 \pm 0.16$ & 0.917 \\
\hline & All ages & $4.22 \pm 0.20$ & $4.29 \pm 0.20$ & 0.125 \\
\hline
\end{tabular}

Table 5. Comparison of $L$. acidophilus and L. casei in female patients and female controls in terms of age groups

\begin{tabular}{|l|c|c|c|c|}
\hline & $\begin{array}{c}\text { Age } \\
\text { groups } \\
\text { (years) }\end{array}$ & $\begin{array}{c}\text { T1DM } \\
\text { patients }\end{array}$ & $\begin{array}{c}\text { Healthy } \\
\text { control } \\
\text { group }\end{array}$ & \multicolumn{1}{|c|}{$\mathbf{p}^{*}$} \\
\hline L.acidophilus & 19-28 Yaş & $4.95 \pm 0.14$ & $4.98 \pm 0.11$ & 0.664 \\
\hline & 31-41 Yaş & $4.89 \pm 0.11$ & $4.90 \pm 0.09$ & 0.798 \\
\hline & 43-56 yaş & $5.01 \pm 0.10$ & $5.06 \pm 0.14$ & 0.196 \\
\hline & Tüm yaşlar & $4.94 \pm 0.13$ & $4.98 \pm 0.12$ & 0.454 \\
\hline L.casei & 19-28 Yaş & $4.20 \pm 0.21$ & $4.31 \pm 0.28$ & 0.340 \\
\hline & 31-41 Yaş & $4.23 \pm 0.28$ & $4.34 \pm 0.27$ & 0.306 \\
\hline & 43-56 yaş & $4.26 \pm 0.19$ & $4.31 \pm 0.16$ & 0.749 \\
\hline & Tüm yaşlar & $4.22 \pm 0.22$ & $4.32 \pm 0.24$ & 0.143 \\
\hline *T1DM: type 1 diabetes mellitus; L.: Lactobacillus *calculated using \\
\hline Mann-Whitney U test & & & \\
\hline
\end{tabular}

in bioinformatics and progression in molecular techniques have enabled comprehensive research in living microorganisms (13). 
There are no published data based on national and international sources regarding L. casei and L. acidophilus species recognized for their probiotic activity in the intestinal microbiota of individuals diagnosed with adult T1DM. In particular, we could only partially compare the findings of our study with those in children since there were no articles with data on adults. Murri et al. (2) reported in 2013 that the amount of Lactobacillus in the intestinal microbiota of the children with T1DM is lower than the control group; Brown et al (14), analyzed the 16s rRNA in the stool samples of 8 children with T1DM and reported that the Lactobacillus. amounts were higher compared to the control group. We are convinced that there is no definite conclusion yet regarding the probiotic activities of $L$. casei and $L$. acidophilus in the intestinal microbiota of patients with T1DM, since the number of cases in these studies was substantially low compared to the number of cases in our study. Also, the test method used in other studies was different from those used in the present study, and they presented only information at the Lactobacillus level and not at the species level. However, although our research included data on humans, we compared our findings with the animal experiments due to the lack of publications on the same subject. Valladares et al. (15) reported that T1DM, normally found on day 69, did not develop until day 141 in diabetes-prone (BB-DP) rats fed with L. johnsonii isolated from diabetes-resistant (BB-DR) rats; they found high bacterial ratios when Lactobacillus was examined in the specimens from the ileal mucosa of these rats. According to the data, it can be thought that T1DM is affected due to the increase in the Lactobacillus species in the intestinal microbiota. Although the Lactobacillus species we examined in our study was different, we found that there was no statisti- cally significant difference in the mean amount of $L$. acidophilus and L. casei in the patients with T1DM compared to the control groups. However, extensive studies in animals are required to determine what changes may occur as a result of the administration of $L$. acidophilus and $L$. casei species to BB-DP rats for extended periods.

\section{CONCLUSION}

The fact that L. acidophilus and L. casei, known for their probiotic effects, do not show any difference in terms of quantity in healthy male and female controls compared to T1DM suggests that more extensive research is needed to determine the location of these bacteria in the mutually triggering cycle of T1DM and intestinal microbiota. We aimed to highlight that limited data are available in this regard based on our findings.

Ethics Committee Approval: Ethics committee approval was received for this study from the Clinical Trials Ethics Committee. (Decision No: 83045809/30339; Date: 31.10.2013).

Informed Consent: Written informed consent was obtained from patients who participated in this study.

Peer-review: Externally peer-reviewed.

Author Contributions: Concept - H.B.T., M.D.; Design - H.B.T., M.D., M.Ö., F.E.T.K.; Supervision - H.B.T., M.D., M.Ö.; Resources - H.B.T., M.D., F.E.T.K., M.Ö., Z.T.; Materials - H.B.T., M.D., Z.T.; Data Collection and/or Processing - M.D., Z.T., F.E.T.K.; Analysis and/or Interpretation - H.B.T., M.D., B.S.K.; Literature Search - H.B.T., M.D., B.S.K.; Writing Manuscript - H.B.T, M.D., B.S.K.; Critical Review - M.D., F.E.T.K., Z.T., M.Ö., B.S.K., H.B.T.

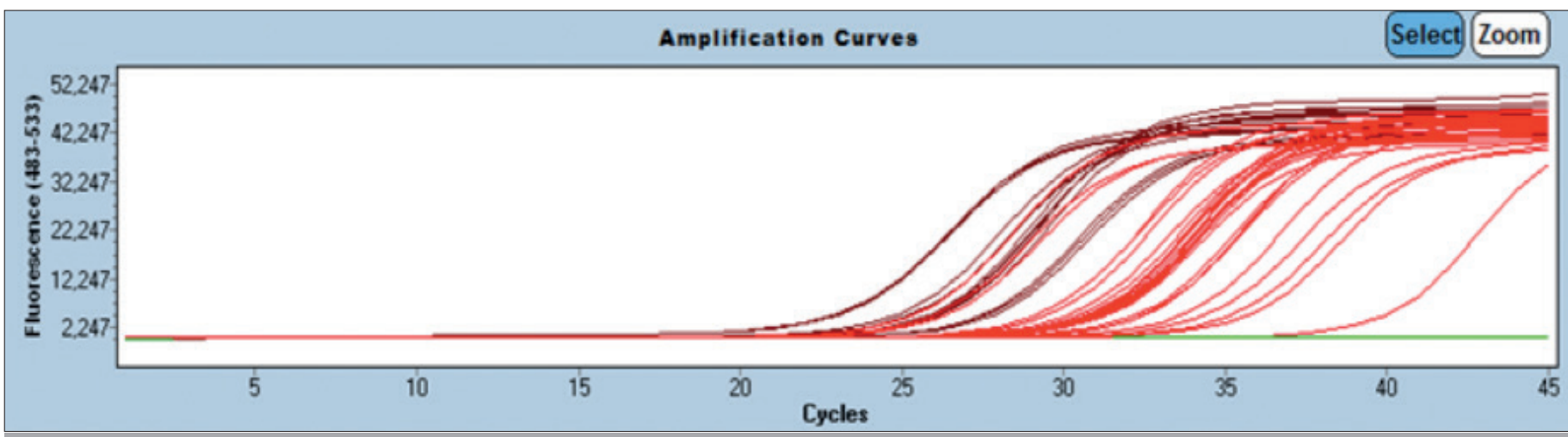

Figure 1. L. casei growth curves

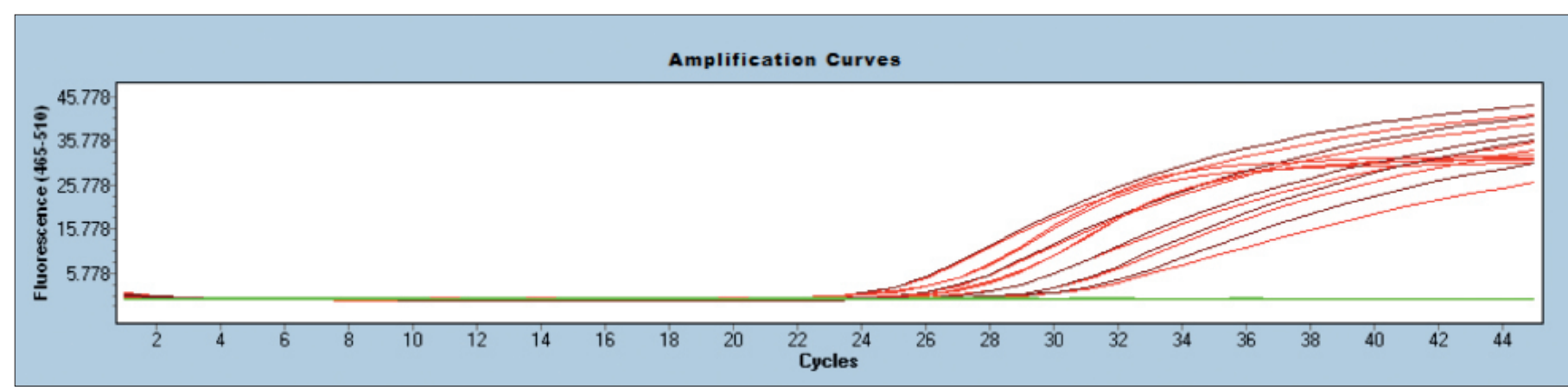

Figure 2. L. acidophilus growth curves 
Conflict of Interest: The authors have no conflict of interest to declare.

Financial Disclosure: The present work was supported by the Research Fund of Istanbul University (Project No. 37749).

\section{REFERENCES}

1. Saleh NM, Raj SM, Smyth DJ, Wallace C, Howson JMM, Bell L, et al. Genetic association analyses of atopic illness and proinflammatory cytokine genes with type 1 diabetes. Diabetes Metab res rev 2011; 27: 838-43. [CrossRef]

2. Murri M, Leiva I, Gomez JM, Cardona F, Soriguer F, Tinahones FJ, et al. Gut microbiota in children with type 1 diabetes differs from that in healty children: a case control study. BMC Medicine 2013; 11: 46. [CrossRef]

3. Gomes AC, Bueno AA, de Souza RGM, Mota JF. Gut microbiota, probiotics and diabetes. Nutrition Journal. 2014; 13: 60. [CrossRef]

4. Westerholm-Ormio M, Vaarala O, Pihkala P, Ilonen J, Savilahti E. Immunologic activity in the small intestinal mucosa of pediatric patients with type 1 diabetes. Diabetes 2003; 52: 2287-95. [CrossRef]

5. Karlsson F, Tremaroli V, Nielsen J, Bäckhed F. Assessing the human gut microbiota in metabolic diseases. Diabetes 2013; 62: 3341-9. [CrossRef]

6. Macpherson AJ, Uhr T. Induction of protective IgA by intestinal dendritic cells carrying commensal bacteria. Science 2004; 303: 1662-5. [CrossRef]

7. Sommer F, Bäckhed F. The gut microbiota--masters of host development and physiology. Nat Rev Microbiol 2013; 11: 227-38. [CrossRef]

8. Ljungberg M, Korpela R, llonen J, Ludvigsson J, Vaarala O. Probiotics for the prevention of beta cell autoimmunity in children at gene- tic risk of type 1 diabetes--the PRODIA study. Ann N Y Acad Sci 2006; 1079: 360-4. [CrossRef]

9. Parra K, Ferrer M, Pi-ero M, Barboza Y, Medina LM. Use of Lactobacillus acidophilus and Lactobacillus casei for a potential probiotic legume-based fermented product using pigeon pea (Cajanus cajan). J Food Prot 2013; 76: 265-71. [CrossRef]

10. CDC. Distribution of Age at Diagnosis of Diabetes Among Adult Incident Cases Aged 18-79 Years. 2011. Available from: URL: http:// www.cdc.gov/diabetes/statistics/age/fig1.htm.

11. Herbel SR, Von Nickisch-Rosenegk M, Kuhn M, Murugaiyan J, Wieler LH, Guenther S. Specific TaqMan Probes for the Identification and Quantification of Lactobacilli in Pharmaceuticals. J Prob Health 2014; 2: 1.

12. Monique H, Knol J. Quantitative Real-Time PCR Analysis of Fecal Lactobacillus Species in Infants Receiving a Prebiotic Infant Formula. App. Env. Mic 2006; 4: 2359-65.

13. NIH HMP Working Group, Peterson J, Garges S, Giovanni M, Mclnnes P, Wang L, et al. The NIH Human Microbiome Project. Genome Res 2009; 19: 2317-23. [CrossRef]

14. Brown CT, Davis-Richardson AG, Giongo A, Gano KA, Crabb DB, Mukherjee $N$, et al. Gut microbiome metagenomics analysis suggests a functional model for the development of autoimmunity for type 1 diabetes. PLoS One 2011; 6: e25792. [CrossRef]

15. Valladares R, Sankar D, Li N, Williams E, Mahmou ASA, Lai K-K, et al. Lactobacillus johnsonii N6.2 mitigates the development of type 1 diabetes in BB-DP rats. PLoS One 2010; 5: e10507. [CrossRef] 